\title{
Nanoinformatics: an emerging area of information technology at the intersection of bioinformatics, computational chemistry and nanobiotechnology
}

\author{
Fernando González-Nilo ${ }^{1 *}$, Tomás Pérez-Acle ${ }^{2}$, Sergio Guínez-Molinos ${ }^{1}$, Daniela A. Geraldo ${ }^{1}$, Claudia Sandoval ${ }^{1}$, \\ Alejandro Yévenes ${ }^{1}$, Leonardo S. Santos ${ }^{1}$, V. Felipe Laurie ${ }^{1}$, Hegaly Mendoza ${ }^{1}$ and Raúl E. Cachau ${ }^{3}$ \\ 1 Universidad de Talca, 2 Norte 685, Casilla 721, Talca, Chile. \\ 2 Computational Biology Laboratory (DLab), Centro de Modelamiento Matemático (CMM), Facultad de Ciencias Físicas y Matemáticas, Universidad de Chile. \\ ${ }^{3}$ Advanced Structure Analysis Collaboratory, ABCC-ISP, Science Applications International Corporation (SAIC)-Frederick, Inc., National Cancer Institute at Frederick, \\ Frederick, Maryland 21702, USA.
}

\begin{abstract}
After the progress made during the genomics era, bioinformatics was tasked with supporting the flow of information generated by nanobiotechnology efforts. This challenge requires adapting classical bioinformatic and computational chemistry tools to store, standardize, analyze, and visualize nanobiotechnological information. Thus, old and new bioinformatic and computational chemistry tools have been merged into a new sub-discipline: nanoinformatics. This review takes a second look at the development of this new and exciting area as seen from the perspective of the evolution of nanobiotechnology applied to the life sciences. The knowledge obtained at the nano-scale level implies answers to new questions and the development of new concepts in different fields. The rapid convergence of technologies around nanobiotechnologies has spun off collaborative networks and web platforms created for sharing and discussing the knowledge generated in nanobiotechnology. The implementation of new database schemes suitable for storage, processing and integrating physical, chemical, and biological properties of nanoparticles will be a key element in achieving the promises in this convergent field. In this work, we will review some applications of nanobiotechnology to life sciences in generating new requirements for diverse scientific fields, such as bioinformatics and computational chemistry.
\end{abstract}

Key words: Bioinformatics, molecular simulation, nanobiotechnology, nanoinformatics, nanomedicine.

\section{INTRODUCTION}

Richard Feynman introduced nanotechnology as a concept in 1979 during a conference at the California Institute of Technology. In that conference, Feynman gave an anticipatory talk, "There is Plenty of Room at the Bottom," suggesting that individual atoms and molecules could be manipulated, allowing the controlled production of materials at the nanometer scale with promising technical, industrial, and biological applications (Drexler, 1992). This conference and its derived material would later be considered the theoretical starting point for the development of nanotechnology. Since then, nanotechnology has created a revolution, not only in the fields of physics, chemistry, materials science, engineering, environmental sensing, manufacturing, and quantum computing, but also with across-the-board applications in clinical research and biotechnology. Consequently, initiatives have created an international focus on new synthesis strategies, structures, phenomena, and properties associated with dimensional length scales residing between 1 and $100 \mathrm{~nm}$ (Tomalia, 2005).

Although many strategies have been applied to advance nanotechnology, a new approach, based on the organization, interpretation, and prediction of the structure and physical-chemical properties of nanoparticles and nanomaterials, is gaining momentum. The applications of computer technologies, information science, and molecular simulations have been gaining terrain as key methodologies to nanobiotechnology and nanoinformatics research; these methodologies are suitable to produce qualitative concepts, insights, and design suggestions. While bioinformatics is frequently related to the use of computational tools to analyze DNA and protein sequence data, nanoinformatics is applied in the context of characterizing particles and materials with application in nano- and biotechnology, by modeling and simulating them, in many instances at the atomic level, using computational chemistry strategies.

Introducing foreign bodies into the complex machinery of the human body is, however, a great challenge. Computeraided methods are the natural option to speed up the development of innovation in life sciences. However, new procedures for annotation and simulation of nanoparticle properties should be developed and analyzed to determine the limitations of computational methods applied in this field.

The introduction of new information techniques to nanobiotechnology problems may accelerate the development of highly specific biomedical treatments, increase their efficiency, and minimize their secondary effects, among other applications. In this contex the concept of nanomedicine emerges, which has advanced rapidly in the last five years. A simple analysis of the number of web links related to the term "nanomedicine" shows exponential growth.

The first nanomaterials for biomedical sciences were designed in 1985, and since 2004, the term "nanomedicine" has been in widespread use. So far, the emergence of modern nano-biomedical sciences has been dominated by applications to biomedical problems, such as technological products from breakthrough synthetic methods in lipid (liposomes), polymer 
(dendrimers), and colloid chemistry (metal colloids), and the discovery of entirely new chemical processes like fullerene and quantum-dot synthesis. All these new molecular systems have potential applications in diagnostics and therapy.

The lack of a common language as a mechanism for sharing knowledge is a huge impediment, especially in new disciplines. This emphasizes the need for governmental and other databases to organize and/or develop joint dictionaries and ontologies so that data can be collected more meaningfully. On the other hand, the nature and the amount of new data from nanotechnology efforts require GRID tools for their rapid analysis. Multi-scale datasets (from eM histopathology to molecular descriptors) are massive (15 Tb with current technologies) and analyses using combined data from multiple sources can only be achieved in a distributed environment, like GRID systems, which is the only realistic way to operate with this huge amount of information that in the near future can be combined with genomic information.

In what follows, we will analyze the state of the art in nanobiotechnology informatics by dividing the problem into four discrete areas, including social aspects (convergence of nanotechnology and medical sciences around nanoinformatic problems); new extension to classical bioinformatics methods; new modelling challenges, and the budding emergence of collaboratory environments, the later being a characteristic element of nearly every new nanoinformatics initiative.

\section{CONVERGING TOWARD NANOBIOTECHNOLOGY AND NANOMEDICINE}

This section will describe some of the tools and technologies that will accelerate the evolution of nanobiotechnology, such as new databases and storage systems adapted to process information generated in nanomedicine, critical for the design, modeling, simulation and visualization of nanosystems applied to the life sciences. As suggested before, the new data and knowledge obtained at the nano-scale level imply the development of new ontologies (nano-ontologies), to achieve a conceptual consensus of all information, terminology, and methodologies used in this field.

Today, nanomedicine has branched out into hundreds of directions; each subdiscipline is developing the ability to manipulate structure and devices at the molecular scale, which can bring enormous and immediate benefits to medicine (ETP Nanomedicine, October 22, 2009; Freitas, 2005). These applications focus on treatment, monitoring, and diagnostics in new methods for drug administration and control of biological systems (ETP Nanomedicine, October 22, 2009; Farokhzad and Langer, 2006; Thierry, 2009).

Economic and other resources have been directed at developing new technologies in nanomedicine to reduce the mortality and morbidity rates, the prevalence of disease and the general social burden (ETP Nanomedicine, October $22,2009)$. The growing interest in nanomedicine and the exponential generation of data at the nano-scale level have enabled interdisciplinary groups to work together to create new nanoparticles with biomedical application. These data require an exhaustive analysis of their physical-chemical properties and an extensive structural characterization (ETP Nanomedicine, October 22, 2009; Farokhzad and Langer, 2006), which involves an intensive use of computational resources.
For these reasons, nanoinformatics emerged to satisfy the need to develop computational tools able to support the analysis of information generated each day in nanomedicine (García-Remesal et al., 2007; Gonzalez-Nilo Danilo and Cachau, 2008; Iglesia et al., 2009). Nanoinformatics was supported in a first stage by the U.S. National Science Foundation (de la Calle et al., 2009) and other international initiatives like the Action-Grid project. Another useful research initiative in nanomedicine is the BioInformatics Resource Inventory (BIRI). BIRI is an approach for automatically discovering and indexing available public bioinformatics resources, using information extracted from scientific literature. This tool is based on a domain-independent approach (De la Calle et al., 2008; GarcíaRemesal et al., 2007), that can be used to create inventories targeting different scientific fields. For now, this approach is currently being applied in the European Commission-funded Action Grid project.

Thus, nanomedicine is a new field gathering the applications of nanotechnologies to healthcare (ETP Nanomedicine, October 22, 2009). This field is led by several expert groups in Europe, such as the Nanomedicine Group of the Observatory for Micro-Nano Technologies (OMNT) (www.omnt.fr) in France, the European Technology Platform (ETP) the Nanomedicine platform (www.etp-nanomedicine. eu), several cluster meetings organized by the European Commission on Personal Health Systems or on Micro-NanoBio Convergence Systems, and some European networks such as Nano2life (http://www.nano2life.org/) and ACTION-Grid (http:/ / www.action-grid.eu/).

With the need to extract, process, analyze, evaluate, and visualize the information generated in nanomedicine at the clinical level, new requirements have emerged for biomedical informatics (BMI). These new challenges will be resolved through the use of nanoinformatics and convergence technologies (NBIC) (Proyecto NBIC; Rodriguez, 2008), specifically information technology and communication technologies (ICTs) (Sommerfeld et al., 2009; Talbi and Zomaya, 2007).

At the same time, a bioinformatics (databases/-omics) and computational chemistry approach (design/modeling/ simulation) can be used to evaluate nanosystems for nanomedicine in therapy and diagnostics. Initially, this area was unexploited due to the complex nature of biological and pharmacological systems, and also due to the expertise and interdisciplinary efforts required to formulate computational models for complex phenomena at the nano-scale level (Tentoni, 2003).

The application of nanosystems in personalized medicine, such as drug delivery systems and nanosystems for diagnostics and therapy, requires developing computational tools and methodologies for its modeling and simulation and the implementation of strategies to interpret the information generated after the interaction of specific organisms with these nanosystems.

Recent studies (Milanesi et al., 2009) have established a scheme where all the aforementioned components converge around the study of a complex biomedical system (see Figure 1). Several nanotechnological research lines emerge in health that can provide new ideas and concepts for solving pathological mechanisms and lead to novel therapeutic orientations. 


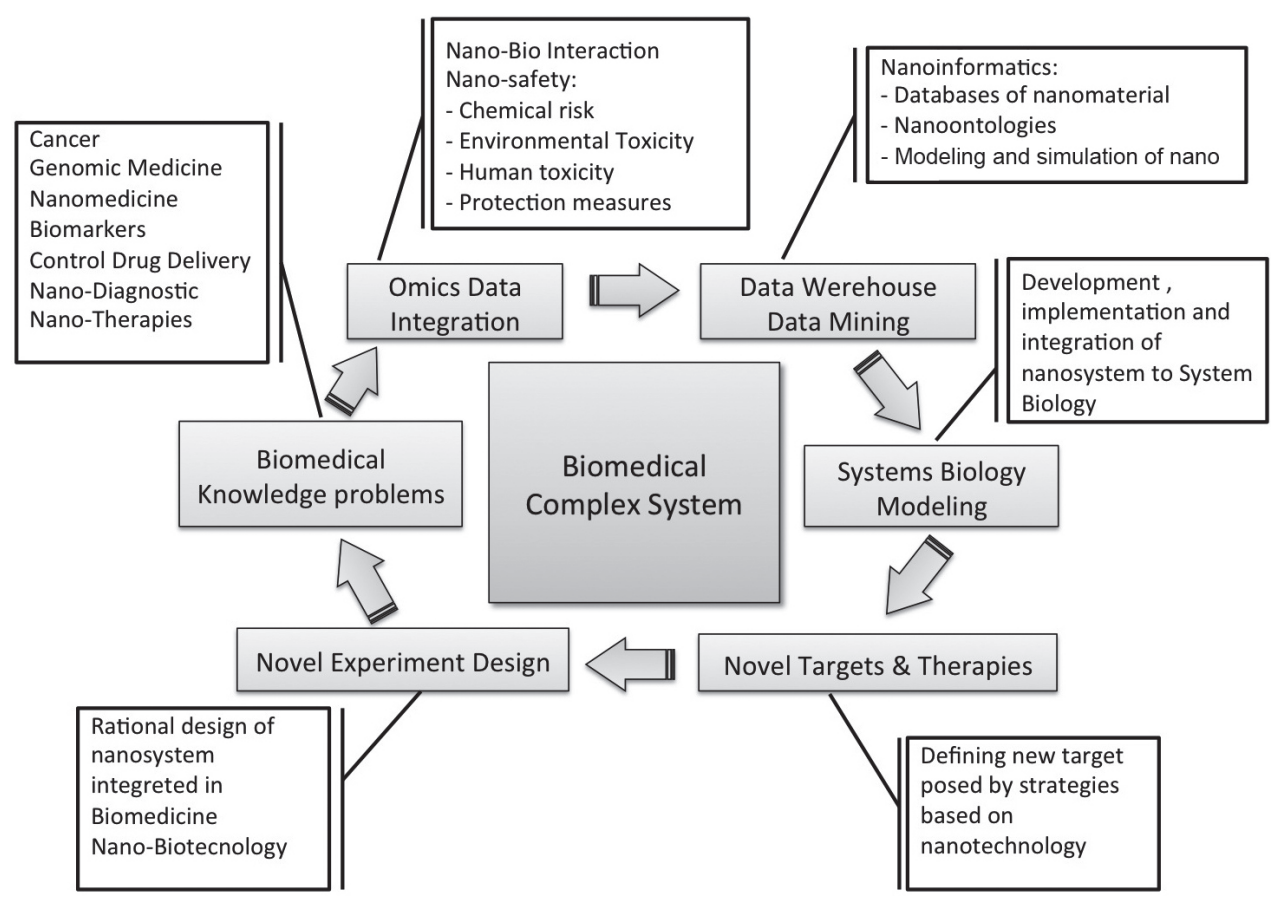

Figure 1. Scheme for the convergence of different research lines from biomedicine to nanobiotechnology around the complex biomedical system.

\section{NEW CHALLENGES FOR BIOINFORMATICS AND COMPUTATIONAL CHEMISTRY IN NANOBIOTECHNOLOGY}

A computational approach is important in the early stages of project development at the nano-scale level. It can be used as a predictive technique in designing nano-transport systems for specific drugs or molecular devices (Tentoni, 2003; Thierry, 2009). Large molecular systems are used today as vehicles or transportation platforms because they can be modified with various chemical groups that confer solubility, affinity, and selectivity for specific sites of a cell (Kang et al., 2009; Tentoni, 2003; Thierry, 2009).

In recent years, computational molecular design has become an increasingly important field in researching new nanomaterials (Rickman and LeSar, 2003); this results from increased calculational capacity and the consolidation of a number of methodologies of computational chemistry (Gao, 2001).

Computational chemistry is a powerful tool to design, model, simulate, and visualize nanomaterials (Gao, 2001) and nanoparticles, such as dendrimers (Belting and Wittrup, 2009; Diekmann and Lindhorst, 2002; Newkome and Shreiner, 2007; Selim and Lee, 2009), metallic nanoparticles (Lee et al., 2009c; Murali Mohan et al., 2009; Prasad and Jha, 2010), nanocapsules (Fan and Hao, 2009), nanospheres (Lee et al., 2009a), and quantum dots (Kang et al., 2009). These nanoparticles are being used in nanomedicine as carriers, sensors, and systems for early diagnosis of diseases (Belting and Wittrup, 2009; ETP Nanomedicine, October 22, 2009; Kang et al., 2009).

Computer-assisted nanomolecule design has emerged from recent advances in computational chemistry and nanotechnology and is considered well suited for assisting the experimental community in the design of new nanostructures (Bewick et al., 2009). The major advantage of computational nano-design is that it provides a relatively inexpensive and rapid way to explore many structural designs, including the study of stability and prediction of properties (Shapiro et al., 2008).

The application of modeling methods and nano-scale simulation to nano-design demands new methods or the adaptation of the techniques used in computational chemistry, such as classical molecular dynamics simulations (Fermeglia and Pricl, 2009; Gates et al., 2005), molecular mechanics (Shapiro et al., 2008) and quantum mechanics (Gates and Hinkley, 2004; Shapiro et al., 2008). Besides the use of these computational methods at the atomic level, it is necessary to implement new approaches in the use of quantitative structure-activity relationship (QSAR) studies in this field (Shapiro et al., 2008).

Computational chemistry using molecular dynamics (MD) in nanostructures requires a good characterization of physical and chemical properties (Shapiro et al., 2008) to obtain accurate simulation results about the structural and dynamic properties of nanosystems at the atomic level (Gates et al., 2005). The Collaboratory for Structural Nanobiology (CNS) (http:// nanobiology.utalca.cl) is the first initiative in the world that includes a database of nanoparticle structures. The first stage of this initiative includes more than 120 models of dendrimers built using advanced molecular simulation techniques. CNS is an initiative of SAIC-NCI, USA, in collaboration with CBSMUTalca from Chile.

Computational chemistry using molecular mechanics (MM) can be used to determine the optimized structure of nanoparticles or nanomaterials (lowest energy conformation). 
This is based on a model of molecules where spheres describe atoms and springs represent the bonds among them (Gates and Hinkley, 2004). The total energy of the molecule is calculated as the sum of energies implemented in a particular force field (energies of stretching, angles, torsion, $\mathrm{VdW}$ interactions, electrostatic interactions, and hydrogen bonds) (http: / / www.charmm.org/html/ documentation/c34b1/ energy.html). Thus, modeling at the nano-scale requires force fields that are sufficiently accurate for both the inorganic and organic components of the nanostructures. These features are extremely important for determining the 3D structural characteristics of nanostructures.

Computational chemistry also uses quantum mechanics (QM) such as semi-empirical, ab initio, and density functional theory (DFT) to predict the molecular structure at the electronic level of nanomaterials and to compute different molecular descriptors that depend on the electronic configuration of the system (Shapiro et al., 2008). These methods are limited not only by the number of degrees of freedom, but also by the time scale that requires this kind of calculations (http:/ / www.charmm.org/html/documentation/ c34b1/energy.html; Shapiro et al., 2008). For this reason, the application of QM methods to nanoscale simulation for nanodesign demands new methods or an adaptation of the techniques traditionally used.

Several studies have been carried out using a cycle based on theoretical and experimental studies, with the aim of achieving a better understanding of systems at the nano-scale. For example, Haddish-Berhane et al. (Haddish-Berhane et al., 2007) have studied a multiscale framework to integrate current computational approaches at different scales for drug delivery problems based on nanoparticles (Figure 2). It is expected that about $30 \%$ of pharmaceutical expenditure will be based on computer simulation, through an integrated effort between experimental and theoretical groups.

Theoretical models for the design of nanoparticles are diverse and use different approaches developed over the last 40 years in computational chemistry. For example, Deduzzi et al. et al., 2009b), using modeling techniques, have developed a theoretical study about size, shape, and surface of nanoparticles. Such features seem to play an important role when used as carriers and sensor systems in the intravascular journey.

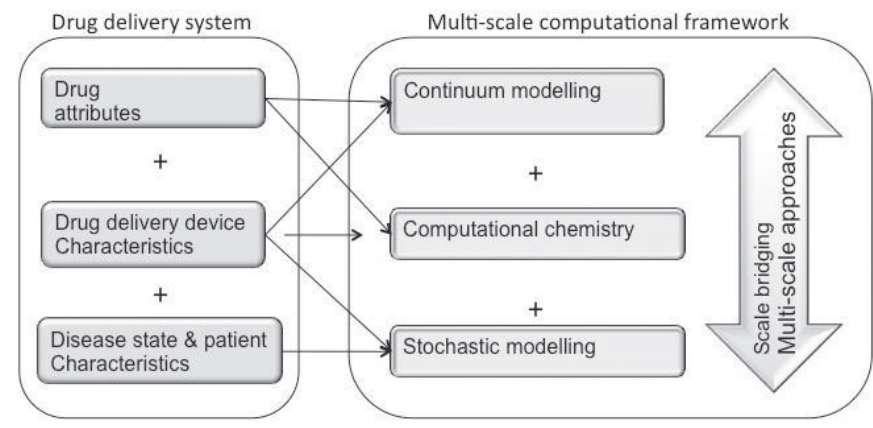

Figure 2. A framework for multi-scale modeling of drug delivery systems using information from drug and vehicle properties, disease pathology, and patient characteristics. Scheme adapted from Haddish-Berhane et al. (Haddish-Berhane et al., 2007).
Another example is the study by Pillay et al. (Sibeko et al., 2009) that employed advanced computational tools to design a drug delivery system based on a biopolymeric membrane. Specifically, the group studied the influence of triethanolamine on the release properties of methotrexate from a composite biopolymeric membrane. Properties such as drug entrapment efficiency and the mechanisms of drug delivery have an important impact on the design of these kinds of systems. These properties require in-depth study and characterization at the molecular level. Thus, the design of new nano devices requires advanced computational tools to accelerate understanding of the mechanics of drug delivery.

Therefore, the need for accuracy and speed in the design of nanostructures requires the development of new computational chemistry methodologies or adaptation of existing ones to generate workflows and protocols to design suitable nanostructures.

\section{MOLECULAR SIMULATIONS: KEY TECHNIQUES TO UNDERSTAND FUNDAMENTAL PHYSICOCHEMICAL PROPERTIES OF NANOPARTICLES}

Simulation techniques have been widely used to model a variety of phenomena through a general approximation that treats the interacting particles as rigid spheres connected by springs. More recently, the development of force fields (Daggett, 2001; MacKerell, et al., 2000; Ponder and Case, 2003) suitable to perform biomolecular simulations permitted the study of diverse atomic level biological systems, ranging from a few thousand atoms (Artigas et al., 2008a; Barria et al., 2009; Gogonea et al., 2001; Gonzalez et al., 2008; Frisch 2004), up to the whole-organism, with the recently reported modelling of the complete TMV virus (Freddolino et al., 2006). Force fields used for biomolecular simulations (Case et al., 2005; MacKerell et al., 2000), such as CHARMM and AMBER, include both bonded and non-bonded interactions between all the represented atoms, plus expressions to model the effect of Van der Waals and Coulomb potentials, incorporating the system's projected long-range effects induced by mass and charge (Daggett, 2001; MacKerell et al., 2000).

Despite the validity of the mathematical expressions that compose the available force fields, parameterization constants are included in all the bonded and non-bonded terms. These constants are fine-tuned, using either pure quantum mechanic calculations (ab initio) or empirically based approaches (Ponder and Case, 2003). When compared to wet-lab experiments, molecular simulation results have proven to be as accurate as typical experimental methods like microcalorimetry (Patra and Karttunen, 2004; Ponder and Case, 2003; Price and Brooks, 2002). Thus, molecular simulations based on force fields have become a popular methodology to explore the behaviour of biomolecules at all the micro-, meso-, and nano-scales.

As noted before, molecular simulation techniques depend on the structure of the biomolecular system to be modelled. Consequently, there is much attention to developing databases to contain molecular structure data. Since the primordial research efforts dedicated to producing crystallographic structures of biomolecules in the 1970s, public databases, such as the Protein Data Bank (PDB; www.pdb.org, Rutgers University, the State University of New Jersey, and the University of California, San Diego, CA, USA), have grown to comprise more than 62.000 biomolecular 3D structures (nearly 
35,000 unique structures). However, the growth of unique folds at PDB and the results of joint international efforts, such as the Structural Genomics Project (Lundstrom, 2007; McGuffin and Jones, 2002; Sali et al., 2007), demonstrate that we know only a portion of the different architectures and macromolecular arrangements in the human body. Moreover, the complexity of the intracellular environment complicates crystallization for many proteins. As a consequence, membrane-integral proteins such as channels and other transporters are usually underrepresented in databases like PDB.

Based on a seminal work from the $1980 \mathrm{~s}$ that demonstrated that the structure is more conserved than the sequence (Chothia and Lesk, 1986; Chothia et al., 1986), new methods to produce molecular models based on reference structures have been developed (Sali and Blundell, 1993; Sali et al., 1995; Sanchez and Sali, 2000). These methods, commonly known as comparative modelling techniques, are suitable under some restrictions, to produce models able to be used as sources for protein engineering (Colombres et al., 2008; Eyzaguirre et al., 2004) and computer-based drug design (Lagos et al., 2008; Lizama et al., 2009; Vasquez et al., 2007), to explore structure-function relationships (Artigas et al., 2008b; Barria et al., 2009; Carvajal et al., 2003; Ehrenfeld et al., 2008; Stange et al., 2008; Strobel et al., 2005; Tischler et al., 2005), and signal-transducing mechanisms (Gonzalez et al., 2008; Inestrosa et al., 2005; Strobel et al., 2004), among a variety of applications.

Extensive efforts have been made at the experimental level to characterize the fundamental physicochemical properties of nanoparticles with potential applications in biomedical sciences. However, all these efforts have faced the limits of current experimental techniques, because the nanoscale has proven to be too small for light microscopy, while too polydisperse for x-ray crystallography, too heterogeneous for NMR, and too "wet" for electron microscopy (Lu et al., 2006). Under these circumstances, molecular modelling and simulation techniques have arisen as key methodologies to nanobiotechnology research, suitable to produce qualitative concepts, insights, and design suggestions. Thus, quantum mechanics, molecular modelling and molecular simulation techniques provide representations of nanosystems at the atomic level with electronic resolution, offering a suitable framework for the characterization of diverse physical-chemical properties of nanosystems. Advancing in these efforts, the reports of several molecular dynamics (MD) simulations of nanoparticles and other nanosystems demonstrated the suitability of these computer-based techniques to explore and understand basic properties of nanoparticles and nanomaterials (Cieplak and Thompson, 2008; Khurana et al., 2006; Martin et al., 2008; Zimmerli and Koumoutsakos, 2008). Moreover, these tools provide a unique source of information not only to model basic nanoparticle properties, but also to gain insight into interactions with biological systems. The application of computer-intensive methods like hybrid quantum mechanics and molecular dynamic (QM/MM) simulations, enriched with proper algorithms to efficiently sample the vast conformational space, will permit characterizing a wide variety of nanoparticle properties, obtaining insights into the biological phenomena that command nanoparticle recognition by physiological systems (Arayne et al., 2007; Archakov and Ivanov, 2007; Bianco, 2004).

\section{DEVELOPMENT OF COLLABORATIVE NETWORK PLATFORMS FOR NANOBIOTECHNOLOGY}

\section{5-a. Design web portals}

To facilitate data-sharing (recent literature, tutorials, papers, links, and access points to nanomedical databases; jobs, and news, updated daily) in the research community to expedite and validate the use of nanoparticles, nanomaterials, and nanosystems in nanomedicine (ETP Nanomedicine, October 22, 2009; Gordon and Sagman, 2003). Nanowerk Nanotechology Portal (http://www.nanowerk.com), NanoLink (http:// www.nano-link.net), and CaNanoLab (http://cananolab. abcc.ncifcrf.gov) are clear examples of portals dedicated to promoting the information generated in nanomedicine and nanotechnology. The first is a portal with a great variety of links to and directories about nano research, daily news, and nanotechnology feature articles, reports, an events calendar, and a nanomaterial database focused on nanomedicine (NanoLink is a web portal). The second portal links to sites that focus on life quality through technological innovation (LINK=Life quality through Innovation by a Network of Knowledge). NanoLINK will be a consolidated network of networks focused on nanotechnology (nanoLINKnet) (Nanowerk Nanotechnology Portal). CaNanoLab is also a web portal focused on dissemination of nanobiological information across the scientific community (The Cancer Nanotechnology Laboratory (caNanoLab) Portal).

\section{5-b. Implementation and maintenance of forums}

Forums provide a platform of interactive communication to discuss the new possibilities offered by nanotechnology in medicine and thus promote technology and information transfer among different areas of science, health, the pharmaceutical industry, and education, among others, sustained through nanoinformatics. Such forums include the Nanoforum (http://www.nanoforum.org/), NanoNewsBoard Forum (http://www.amtexpo.com/nano/), and the Institute of Nanotechnology Forum (http:/ / www.nano.org.uk/forum/ index.php). The Nanoforum was developed by the European Commission through FP5 to disseminate the advances of different areas of nanotechnology, including, of course, the development of nanomedicine, its current outlook, and its projections based on the successful discussion of nano-scale research (Funding and Support for International Nanotechnology Collaborations Nanoforum report, December 2005). The second forum, NanoNewsBoard, is a nanotechnology forum sponsored by Access Multimedia Technology, Inc. (USA) (NanoNewsBoard); and the third forum was implemented by the Institute of Nanotechnology (IoN-UK) (Institute of Nanotechnology Forum). Both forums contain nanotechnology news, including nanomedicine (ETP Nanomedicine, October $22,2009)$. These forums update users on the latest advances in applying nanotechnology to medicine.

\section{5-c. Development of thematic networks and collaboration}

Nanotechnology networks and collaborations are being developed to facilitate interaction among professionals (collaborations among groups with different expertise and resources [technical, scientific, social and political]) working at 
the intersection between biomedical information and nanoscale health information (Funding and Support for International Nanotechnology Collaborations Nanoforum report, December 2005; Gonzalez-Ibanez et al., 2009). These networks are needed so experts can share (Open access and dissemination of data and tools, i.e., Open Source), promote, and improve standards of biomedical information generated at the nano-scale (Nanohub Forum; National Institutes of Health [NIH], 2006) and allow users anywhere in the world easy access to information. Examples of current thematic networks and collaborations are: The Collaboratory for Structural Nanobiology (CSN) (http:/ / csn.ncifcrf.gov/csn), the nanoHUB (http://nanohub.org/), and NanoMedNet (http://www.nano.org.uk/nanomednet/). The first is a nanobioinformatic web service dedicated to collecting, curating, and correlating structural, physicalchemistry, biological, and biomedical data (The Collaboratory for Structural Nanobiology). The second is a web platform for research, education, and collaboration in nanotechnology (Nanohub Forum). The third, NanoMedNet, is a collaboration web platform that promotes information about various aspects of the emerging field of nanomedicine and develops services, tools, and education and training for medical professionals related to nanomedicine (NanoMedNet).

\section{5-d. Creation of storage systems and data exchange}

The major increase of data and information generated through measurement or calculation of physical and chemical properties of nanostructures and nanomaterials (The cancer Nanotechnology Laboratory [caNanoLab] Portal), mathematical models from clinical nanomedicine (Bewick et al., 2009), taxonomy of nanomedical application (Gordon and Sagman, 2003), nano-ontologies (The cancer Biomedical Informatics Grid [caBIG]), high-throughput experimentation/discovery (Tentoni, 2003), tools for visual analysis of nanoimages (Mauger et al., 2007) and data-mining of biomedical data (Zweigenbaum et al., 2007), require the creation and implementation of systems and tools for sharing and storing this information.

The creation of databases or repositories (Database of Nanoparticles; Mauger et al., 2007; Sommerfeld et al., 2009) to allow the exchange of information about the 3-D structural and data of the physical and chemicals properties of nanoparticles with biomedical applications, such as dendrimers, nanotubes and metal particles, and quantum dots, among others, is critical for the multidisciplinary development of nanomedicine.

Biomedical data are being generated at different levels. Specifically, the atomic level (nanomedicine) has seen an explosive increase (ETP Nanomedicine, October 22, 2009). This large flow of information requires secure and easily available storage systems. The current information storage systems, called data warehouses, can be expanded to accommodate the information generated in nanomedicine. Thus, the data warehouses (Sommerfeld et al., 2009; Staggers et al., 2008; Talbi and Zomaya, 2007) can be optimized through nanoinformatic tools and the technologies of information and communication (TICs) as storage systems for nano-scale systems useful in medicine.

Several projects in this area have been developed. This is the case with the structural database CSN (http:/ / nanobiology. utalca.cl), The CaNanoDB (https://gforge.nci.nih.gov/ projects/canano/) and The ICON EHS Database (http://icon. rice.edu/research.cfm). The first is a structural database of various nanoparticles with possible nanomedical applications. This site offers downloadable nanopdb files, related research data, and resources for visualization of different nanoparticles, such as dendrimers, nanotubes and metallic particles (CSN). The second, caNano Database (CaNanoLab), includes all available technologies and a toolbox for modeling targeted drug delivery and diagnostics using nanoparticles as transport platforms (The cancer Nanotechnology Laboratory [caNanoLab] Portal). The third project is a database that contains summaries (abstracts) and citations for research papers related to the health and safety implications of nanoscale materials (The ICON EHS Database).

\section{CONCLUSION}

Bioinformatics and molecular simulations have evolved around biotechnology related problems helping the researcher explore complex problems from genome analysis to protein structure. Now, the accelerated convergence of biotechnology and nanotechnology poses new challenges to the information and modeling fields. The newer scientific fields of nanobiotechnology and nanomedicine present a great opportunity for the scientific community to merge many of the concepts and tools developed during the past few decades in computational chemistry and computational biology. The tools of these fields, such as databases, storage, ontologies, and annotation (bioinformatics), should be merged with design, modeling, simulation, and visualization (computational chemistry) of nanosystems, to generate a new sub-discipline: nanoinformatics.

The applications of nanotechnology in medicine and biotechnology require advanced approaches to manipulate nanoparticles data at the molecular level (nano-scale); these approaches are complex and are frequently handled through the implementation of collaborative networks and the creation of web platforms for sharing and discussing the knowledge generated.

As indicated in the previous sections, the impact of molecular modelling and simulations in nanobiotechnology has been steadily increasing during the last decade. Molecular modelling and simulations offer a unique way to explore interactions at different scales that range from thousands of atoms, to even millions of them. Through these simulations, fundamental physicochemical properties of nanoparticle and other nanoscale systems can be studied. The ever-increasing capacity of modern computer platforms, together with a systematic price reduction, will allow the embedding of molecular simulations in different nanotechnology sub-fields. The identification of the intermediate complexity modules that define and control the properties of complex nanodevices will be a main objective of many of these computer simulations given the importance of modular approaches in the rational design of engineered nanomaterials.

The implementation of new database schemes suitable to store and to process data generated in nanobiotechnology connecting physical, chemical, and biological properties of the nanoparticle- will be a key element in deriving the knowledge needed to develop this quality of information.

Thus we can envision the emergence of nanoinformatics as a new discipline comprising the vast set of computer-related tools to model, store, and analyze nanotechnology highly 
diverse data with an increasing role of atomic level simulation tools in the nanodesign cycle.

The implementation of these new techniques may accelerate the development of highly specific biomedical treatments through design, increasing nanobiomaterials efficacy, specificity and bioavailability, while minimizing secondary effects, opening the door to a new era of personalized medicine with materials designed from the bottom up. (Drexler, 1992, citing Feynman, 1959).

\section{ACKNOWLEDGMENT}

This review was supported in part by ACTION-GRID project, PBCT Anillo Cientifico ACT/24, Fondecyt Project 3100037 and 1100882 and Instituto Milenio Centro Interdisciplinario de Neurociencias de Valparaiso (CINV). We thank Fabian Avila (UTalca) and Raul Araya-Secchi (UChile) for their great support to this initiative.

This work was funded in part with funds from the National Cancer Institute, National Institutes of Health, under contracts No. N01-CO-12400 and HHSN261200800001E. The content of this publication does not necessarily reflect the views or policies of the Department of Health and Human Services, nor does mention of trade names, commercial products, or organizations imply endorsement by the U.S. government.

\section{REFERENCES}

ACTION-GRID PROJECT. PORTAL, URL: (HTTP:/ / WWW.ACTION-GRID.EU/). vol. Last Access, March 2010.

ARAYNE MS, SULTANA N, QURESHI F (2007) Review: nanoparticles in delivery of cardiovascular drugs. Pak J Pharm Sci 20:340-348.

ARCHAKOV AI, IVANOV YD (2007) Analytical nanobiotechnology for medicine diagnostics. Mol Biosyst 3:336-342.

ARTIGAS RA., GONZÁLEZ A, RIQUELME E, CARVAJAL CA, CATTANI A, MARTíNEZ-AGUAYO A, KALERGIS AM, PÉREZ-ACLE T, FARDELLA CE (2008a) A novel Acth receptor (Mc2r) mutation alters its structure and function, causing familial glucocorticoid deficiency. J Clin Endocrinol Metab.

ARTIGAS RA, GONZÁLEZ A, RIQUELME E, CARVAJAL CA, CATTANI A, MARTÍNEZ-AGUAYO A, KALERGIS AM, PEREZ-ACLE T, FARDELLA CE (2008b) A novel adrenocorticotropin receptor mutation alters its structure and function, causing familial glucocorticoid deficiency. J Clin Endocrinol Metab 93, 3097-3105.

BARRÍA MI, GONZÁLEZ A, VERA-OTÁROLA J, LEÓN U, VOLLRATH V, MARSAC D, MONASTERIO O, PÉREZ-ACLE T, SOZA A, LÓPEZLASTRA M (2009) Analysis of natural variants of the hepatitis $C$ virus internal ribosome entry site reveals that primary sequence plays a key role in cap-independent translation. Nucleic Acids Res 37:957-971.

BELTING M, WITTRUP A (2009) Macromolecular drug delivery: Basic principles and therapeutic applications. Molec Biotechnol 43:89-94.

BEWICK S, YANG R, ZHANG M (2009) Complex mathematical models of biology at the nanoscale. Wiley Interdisciplinary Reviews: Nanomedicine and Nanobiotechnology 1.

BIANCO A (2004) Carbon nanotubes for the delivery of therapeutic molecules. Expert Opin Drug Deliv 1:57-65.

CARVAJAL CA, GONZÁLEZ AA, ROMERO DG, GONZÁLEZ A, MOSSO LM, LAGOS ET, HEVIA MDEL P, ROSATI MP, PÉREZ-ACLE TO, GÓMEZ-SÁNCHEZ CE, MONTERO JA, FARDELLA CE (2003) Two homozygous mutations in the 11 beta-hydroxysteroid dehydrogenase type 2 gene in a case of apparent mineralocorticoid excess. J Clin Endocrinol Metab 88:2501-2507.

CASE DA, CHEATHAM TE 3RD, DARDEN T, GOHLKE H, LUO R, MERZ KM JR., ONUFRIEV A, SIMMERLING C, WANG B, WOODS RJ (2005) The Amber biomolecular simulation programs. J Comput Chem 26:16681688.

CIEPLAK M, THOMPSON D (2008) Coarse-grained molecular dynamics simulations of nanopatterning with multivalent inks. J Chem Phys 128:234906.
COLOMBRES M, GARATE JA, LAGOS CF, ARAYA-SECCHI R, NORAMBUENA P, QUIROZ S, LARRONDO L, PÉREZ-ACLE T, EYZAGUIRRE J (2008) An eleven amino acid residue deletion expands the substrate specificity of acetyl xylan esterase II (AXE II) from Penicillium purpurogenum. J Comput Aided Mol Des 22:19-28.

CHOTHIA C, LESK AM (1986) The relation between the divergence of sequence and structure in proteins. EMBO J 5:823-826.

CHOTHIA C, LESK AM, LEVITT M, AMIT AG, MARIUZZA RA, PHILLIPS SE, POLJAK RJ (1986) The predicted structure of immunoglobulin D1.3 and its comparison with the crystal structure. Science 233:755-758.

DAGGETT V (2001) Molecular dynamics simulations of protein unfolding/ folding. Methods Mol Biol 168:215-247.

DATABASE OF NANOPARTICLES, http://nanobiology.utalca.cl. vol. Last Access, December 2009

DE LA CALLE G, GARCIA-REMESAL M, CHIESA S, DE LA IGLESIA D, MAOJO V (2009) BIRI: a new approach for automatically discovering and indexing available public bioinformatics resources from the literature. BMC Bioinformatics 10:320.

DE LA CALLE G, GARCÍA-REMESAL M, MAOJO V (2008) A method for indexing biomedical resources over the Internet. Studies in Health Technology and Informatics 136:163.

DIEKMANN S, LINDHORST T (2002) Dendrimers. Reviews in Molecular Biotechnology 90, 157-158.

DREXLER KE (1992) Nanotechnology: The past and the future. Science 255, 268-269.

EHRENFELD N, GONZÁLEZ A, CANON P, MEDINA C, PÉREZ-ACLE T, ARCE-JOHNSON P (2008) Structure-function relationship between the tobamovirus TMV-Cg coat protein and the HR-like response. J Gen Virol 89:809-817.

ERICKSON B (2009) Nanomaterial data remain scarce. Chemical \& Engineering 87:42. ETP NANOMEDICINE, HTTP:// WWW.ETP-NANOMEDICINE. EU / PUBLIC/ PRESS-DOCUMENTS / PUBLICATIONS / 091022_ETPN_REPORT_2009. PDF (October 22, 2009). Roadmaps in Nanomedicine, vol. Last Access, December 2009.

EYZAGUIRRE J, SIGALA C, PÉREZ-ACLE T, CORTES P, PEIRANO A (2004) Importance of the "thumb" for the catalytic activity of endoxylanase B (Xyn B) from Penicillium purpurogenum. Faseb J 18:C146-C147.

FAN D, HAO J (2009) Magnetic aligned vesicles. Journal of Colloid and Interface Science.

FAROKHZAD O, LANGER R (2006) Nanomedicine: developing smarter therapeutic and diagnostic modalities. Advanced Drug Delivery Reviews 58:1456-1459.

FERMEGLIA M PRICL S (2009) Multiscale molecular modeling in nanostructured material design and process system engineering. Computers and Chemical Engineering 33:1701-1710.

FREDDOLINO PL, ARKHIPOV AS, LARSON SB, MCPHERSON A, SCHULTEN K (2006). Molecular dynamics simulations of the complete satellite tobacco mosaic virus. Structure 14:437-449.

FREITAS R (2005) What is nanomedicine? Disease-a-Month 51:325-341.

FUNDING AND SUPPORT FOR INTERNATIONAL NANOTECHNOLOGY COLLABORATIONS NANOFORUM REPORT, http:/ / www.nanoforum. org. (December 2005). vol. Last Access, December 2009.

GAO H (2001) Modelling strategies for nano-and biomaterials. European White Book on Fundamental Research in Materials Science. Stuttgart (Germany): Max Planck Gesellschaft, GMBH 144-148.

GARCÍA-REMESAL M, MAOJO V, CRESPO J, BILLHARDT H (2007) Logica schema acquisition from text-based sources for structured and nonstructured biomedical sources integration, vol. 2007, pp. 259. American Medical Informatics Association.

GATES T, HINKLEY J (2004) Computational materials: Modeling and simulation of nanostructured materials and systems, vol. 2, pp. 18721876. Citeseer.

GATES T, ODEGARD G, FRANKLAND S, CLANCY T (2005) Computational materials: multi-scale modeling and simulation of nanostructured materials. Composites Science and Technology 65, 2416-2434.

GOGONEA V, SUÁREZ D, VAN DER VAART A, MERZ KM JR (2001) New developments in applying quantum mechanics to proteins. Curr Opin Struct Biol 11:217-223.

GONZÁLEZ-IBANEZ A, GONZÁLEZ-NILO F, CACHAU R (2009) The Collaboratory for Structural Nanobiology. Biophys J 96:49.

GONZÁLEZ-NILO D, CACHAU R (2008) Nanoinformatics versus bioinformatics. 5 RIB (Red Iberoamericana de Bioinformática) Congress Pontificie U. Catolica de Chile, Chile

GONZÁLEZ A, DURAN LS, ARAYA-SECCHI R, GARATE JA, PESSOAMAHANA CD, LAGOS, C. F. \& PÉREZ-ACLE T (2008) Computational 
modeling study of functional microdomains in cannabinoid receptor type 1. Bioorg Med Chem 16:4378-4389.

GORDON N, SAGMAN U (2003) Nanomedicine Taxonomy of the Canadian Institute for Health Research (CIHR).

HADDISH-BERHANE N, RICKUS J, HAGHIGHI K (2007) The role of multiscale computational approaches for rational design of conventional and nanoparticle oral drug delivery systems. Internat J Nanomed 2:315. http: / / www.charmm.org/html/ documentation/c34b1/energy.html, U., vol. Last Access, March 2010

IGLESIA DDL, CHIESA S, KERN J, MAOJO V, MATIN-SÁNCHEZ F, POTAMIAS G (2009) Nanoinformatics: New challenges for biomedical informatics at the nano level. Medical Informatics in a United and Healthy Europe.

INESTROSA NC, ÁLVAREZ A, DINAMARCA MC, PÉREZ-ACLE T, COLOMBRES M (2005) Acetylcholinesterase-amyloid-beta-peptide interaction: effect of Congo Red and the role of the Wnt pathway. Curr Alzheimer Res 2:301-306.

INSTITUTE OF NANOTECHNOLOGY FORUM, URL: http://www.nano. org.uk/forum/index.php. vol. Last Access, March 2010.

KANG W, CHAE J, CHO Y, LEE J, KIM S (2009) Multiplex imaging of single tumor cells using quantum-dot-conjugated aptamers. Small (Weinheim an der Bergstrasse, Germany).

KHURANA E, NIELSEN SO, ENSING B, KLEIN ML (2006) Self-assembling cyclic peptides: molecular dynamics studies of dimers in polar and nonpolar solvents. J Phys Chem B 110:18965-18972.

LAGOS CF, CABALLERO J, GONZÁLEZ-NILO FD, DAVID PESSOAMAHANA C, PÉREZ-ACLE T (2008) Docking and quantitative structure-activity relationship studies for the bisphenylbenzimidazole family of non-nucleoside inhibitors of HIV-1 reverse transcriptase. Chem Biol Drug Des 72:360-369.

LEE H, YANG H, HOLLOWAY P (2009a) Functionalized CdS nanospheres and nanorods. Physica B: Physics of Condensed Matter

LEE S, FERRARI M, DECUZZI P (2009b) Shaping nano-/micro-particles for enhanced vascular interaction in laminar flows. Nanotechnology 20:495101.

LEE W, PIAO L, PARK C, LIM Y, DO Y, YOON S, KIM S (2009c) Facile synthesis and size control of spherical aggregates composed of $\mathrm{Cu} 2 \mathrm{O}$ nanoparticles. Journal of Colloid and Interface Science.

LIZAMA C, LAGOS CF, LAGOS-CABRE R, CANTUARIAS L, RIVERA F, HUENCHUNIR P, PEREZ-ACLE T, CARRION F, MORENO RD (2009) Calpain inhibitors prevent p38 MAPK activation and germ cell apoptosis after heat stress in pubertal rat testes. J Cell Physiol 221:296-305.

Lu D, Aksimentiev A, Shih AY, Cruz-Chu E, Freddolino PL, Arkhipov A, Schulten K. (2006) The role of molecular modeling in bionanotechnology. Phys Biol 3:S40-53.

LUNDSTROM K (2007) Structural genomics and drug discovery. J Cell Mol Med 11:224-238.

FRISCH MJ, G. W. T., SCHLEGEL HB, SCUSERIA GE, ROBB MA CHEESEMAN JR, MONTGOMERY JA JR, VREVEN T, KUDIN KN, BURANT JC, MILLAM JM, IYENGAR SS, TOMASI J, BARONE V, MENNUCCI B, COSSI M, SCALMANI G, REGA N, PETERSSON GA, NAKATSUJI H, HADA M, EHARA M, TOYOTA K, FUKUDA $\mathrm{R}$, HASEGAWA J, ISHIDA M, NAKAJIMA T, HONDA $Y$, KITAO O, NAKAI H, KLENE M, LI X, KNOX JE, HRATCHIAN HP, CROSS JB, BAKKEN V, ADAMO C, JARAMILLO J, GOMPERTS R, STRATMANN RE, YAZYEV O, AUSTIN AJ, CAMMI R, POMELLI C, OCHTERSKI JW, AYALA PY, MOROKUMA K, VOTH GA, SALVADOR P, DANNENBERG JJ, ZAKRZEWSKI VG, DAPPRICH S, DANIELS AD, STRAIN MC, FARKAS O, MALICK DK, RABUCK AD, RAGHAVACHARI K, FORESMAN JB, ORTIZ JV, CUI Q, BABOUL AG, CLIFFORD S, CIOSLOWSKI J, STEFANOV BB, LIU G, LIASHENKO A, PISKORZ P, KOMAROMI I, MARTIN RL, FOX DJ, KEITH T, AL-LAHAM MA PENG CY, NANAYAKKARA A, CHALLACOMBE M, GILL PMW, JOHNSON B, CHEN W, WONG MW, GONZALEZ C, POPLE JA (2004) Gaussian (ed. Gaussian I), Wallingford CT:

MACKERELL AD JR, BANAVALI N, FOLOPPE N (2000) Development and current status of the CHARMM force field for nucleic acids. Biopolymers 56:257-265.

MARTIN W, ZHU W, KRILOV G (2008) Simulation study of noncovalen hybridization of carbon nanotubes by single-stranded DNA in water. J Phys Chem B 112:16076-16089.

MAUGER B, HUNTER J, DRENNAN J, WRIGHT A, OHAGAN T (2007) Building a data grid for the Australian Nanostructural Analysis Network, pp. 312-319. IEEE Computer Society: Washington, DC, USA.

MCGUFFIN LJ, JONES DT (2002) Targeting novel folds for structural genomics. Proteins 48:44-52.
MILANESI L, ROMANO P, CASTELLANI G, REMONDINI D, LIÚ P (2009) Trends in modeling biomedical complex systems. BMC Bioinformatics 10:I1.

MURALI MOHAN Y, VIMALA K, THOMAS V, VARAPRASAD K, SREEDHAR B, BAJPAI S, MOHANA RAJU K (2009) Controlling of silver nanoparticles structure by hydrogel networks. Journal of Colloid and Interface Science.

NANOHUB FORUM NNFCN http://www.nanohub.org vol. Last Access, December 2009.

NANOLINK is a portal web, http://www.nano-link.net Nano life quality through innovation by a network of knowledge, vol. Last Access, December 2009.

NANOMEDNET http://www.nano.org.uk/nanomednet/ vol. Last Access, March 2010.

NANONEWSBOARD FORUM http://www.amtexpo.com/nano/ vol. Last Access, March 2010.

NANOWERK NANOTECHNOLOGY PORTAL http:/ / www.nanowerk.com vol. Last Access, December 2009.

NATIONAL INSTITUTES OF HEALTH (NIH), NIOHRFMRN http:// hidroadmap.nih.gov/nanomedicine (2006) vol. Last Access, December 2009.

NEWKOME G, SHREINER C (2007) Poly (amidoamine), polypropylenimine, and related dendrimers and dendrons possessing different 12 branching motifs: An overview of the divergent procedures. Polymer.

PATRA M, KARTTUNEN M (2004) Systematic comparison of force fields for microscopic simulations of $\mathrm{NaCl}$ in aqueous solutions: diffusion, free energy of hydration, and structural properties. J Comput Chem 25:678-89.

PONDER JW, CASE DA (2003) Force fields for protein simulations. Adv Protein Chem 66:27-85.

PRASAD K, JHA A (2010) Biosynthesis of CdS nanoparticles: An improved green and rapid procedure. Journal of Colloid and Interface Science 342:68-72.

PRICE DJ BROOKS CL 3RD (2002) Modern protein force fields behave comparably in molecular dynamics simulations. J Comput Chem 23:1045-1057.

PROYECTO NBIC http:/ / biotic.isciii.es/Biotic/ NBIC.html. vol. Last Access, March 2010.

RICKMAN J LESAR R (2003) Computational Materials Research.

RODRIGUEZ A (2008) NBIC-NANO, BIO, INFO, COGNO LA CONVERGENCIA DE TECNOLOGIAS. La Habana, Cuba.

SALI A BLUNDELL TL (1993) Comparative protein modelling by satisfaction of spatial restraints. J Mol Biol 234:779-815.

SALI A, LIMA CD, KOSTIC M (2007) Structural genomics. Structure 15:1341.

SALI A, POTTERTON L, YUAN F, VAN VLIJMEN H, KARPLUS M (1995) Evaluation of comparative protein modeling by MODELLER. Proteins 23:318-326.

SANCHEZ R, SALI A (2000) Comparative protein structure modeling. Introduction and practical examples with modeller. Methods Mol Biol 143:97-129.

SELIM W, LEE C (2009) Bioinspired application of dendrimers: From biomimicry to biomedical applications. Prog Polymer Sci 34:

SHAPIRO B, BINDEWALD E, KASPRZAK W, YINGLING Y (2008) Protocols for the in silico design of RNA nanostructures. Methods Molec Biol 474:93.

SIBEKO B, PILLAY V, CHOONARA Y, KHAN R, MODI G, IYUKE S, NAIDOO D, DANCKWERTS M (2009) Computational molecular modeling and structural rationalization. Biomedical Materials 4:015014.

SOMMERFELD D, LINGNER T, STANKE M, MORGENSTERN B, RICHTER H (2009) AUGUSTUS AT MEDIGRID: Adaption of a bioinformatics application to grid computing for efficient genome analysis. Future Generation Computer Systems 25:337-345.

STAGGERS N, MCCASKY T, BRAZELTON N, KENNEDY R (2008) Nanotechnology: The coming revolution and its implications for consumers, clinicians, and informatics. Nursing Outlook 56:268-274.

STANGE C, MATUS JT, DOMÍNGUEZ C, PÉREZ-ACLE T, ARCE-JOHNSON $\mathrm{P}$ (2008) The N-homologue LRR domain adopts a folding which explains the TMV-Cg-induced HR-like response in sensitive tobacco plants. J Mol Graph Model 26:850-860.

STROBEL P, ALLARD C, ASPILLAGA A, PEREZ-ACLE T, LEIGHTON $F$ (2004) Role of glucose transporters (GLUT) on flavonoid transport. Free Radical Biology and Medicine 36:S151-S151.

STROBEL P, ALLARD C, PÉREZ-ACLE T, CALDERÓN R, ALDUNATE R, LEIGHTON F (2005) Myricetin, quercetin and catechin-gallate inhibit glucose uptake in isolated rat adipocytes. Biochem J 386:471-478.

TALBI E, ZOMAYA A (2007) Grid Computing for Bioinformatics and Computational Biology. Wiley-Interscience. 
TENTONI L (2003) A model-based approach to the assessment of physicochemical properties of drug delivery materials. Computers \& Chemical Engineering 27;

THE CANCER BIOMEDICAL INFORMATICS GRID (CABIG) https:/ / cabig. nci.nih.gov/overview/. vol. Last Access, March 2010.

THE CANCER NANOTECHNOLOGY LABORATORY (CANANOLAB) PORTAL: http:/ / cananolab.abcc.ncifcrf.gov/caNanoLab/welcome.do. vol. Last Access, March 2010.

THE COLLABORATORY FOR STRUCTURAL NANOBIOLOGY (CSN) http:/ / csn.ncifcrf.gov/csn. vol. Last Access, March 2010.

THE ICON EHS DATABASE http://icon.rice.edu/research.cfm. vol. Last Access, March 2010.

THIERRY B (2009) Drug nanocarriers and functional nanoparticles: Applications in cancer therapy. Curr Drug Deliv 6:391-403.

TISCHLER ND, GONZALEZ A, PEREZ-ACLE T, ROSEMBLATT M, VALENZUELA PD (2005) Hantavirus Gc glycoprotein: evidence for a class II fusion protein. J Gen Virol 86:2937-2947.
TOMALIA DA (2005) The dendritic state. Materials Today 8:34-46.

VASQUEZ D, LAGOS CF, MELLA-RAIPAN J, GONZALEZ L, EBENSPERGER R, ALVAREZ-FIGUEROA MJ, SAEZ E, PESSOAMAHANA H, ARAYA-SECCHI R, GONZALEZ-WONG A, PEREZACLE T, PESSOA-MAHANA CD (2007) 1-benzoyl-2-(2-nitrophenyl)-1Hbenzimidazole derivatives: A novel approach to the development of new HIV-1 reverse transcriptase inhibitors. Journal of the Chilean Chemical Society 52:1281-1287.

ZIMMERLI U, KOUMOUTSAKOS P (2008) Simulations of electrophoretic RNA transport through transmembrane carbon nanotubes. Biophys J 94:2546-2557.

ZWEIGENBAUM P, DEMNER-FUSHMAN D, YU H, COHEN K (2007) Frontiers of biomedical text mining: current progress. Briefings Bioinformatics 8:358. 
